\title{
BAD BREATH AND ITS ASSOCIATION WITH AGE AND
} GENDER

\author{
Vladimir Panov \\ Department of Conservative Dentistry and Oral Pathology, Faculty of Dental Medicine, \\ Medical University of Varna
}

\begin{abstract}
Halitosis is a health condition associated with an unpleasant odor from the oral cavity. The origin of bad breath may be related to systemic and oral conditions, but the large percentage of cases (about $85 \%$ ) are related to oral factors.

Our aim was to investigate the presence and degree of halitosis in healthy patients and to compare it according to age and gender. We examined 79 healthy patients with an apparatus to measure bad breath - HC-212SF FitScan Breath Checker of Tanita Corporation of America, Inc.

We obtained a result of 0.87 for the group under 18 years old, 1 for the group 19-51 years old and 1.5 for the group over 51 years. In our study the average value was 0.88 for men and 1.39 for women.

Of all tested individuals about one-third did not show any bad odor, while 77 percent had some degree of positive result. Considering the condition in relation to gender, we observed that $43 \%$ of men and $25 \%$ of women do not have a bad breath odor.
\end{abstract}

About $29 \%$ had the lowest positive value (1), value 2 - about $28 \%$ and only $1.3 \%$ had a very high degree of halitosis.

This study indicates augmentation of the values of bad breath with the increasing of age. Women suffer from halitosis more often. In all age groups we observed higher degree of bad breath in women.

Keywords: bad breath, halitosis, age, gender

\section{INTRODUCTION}

Halitosis is a health condition characterized by unpleasant odor from the oral cavity. The exact mechanism is unclear, but it has been attributed mainly to oral pathologies. It is estimated to be found

Address for correspondence:

Vladimir Panov

Faculty of Dental Medicine,

Medical University of Varna

84 Tzar Osvoboditel Blvd.

9002 Varna, Bulgaria

e-mail:vl_panov@abv.bg

Received: November 3, 2016

Accepted: November 9, 2016 in around 50 to $60 \%$ of the population and it carries serious social and personal repercussions $(1,2)$.

Oral causes are linked to deep carious lesions, oral infections, periodontal disease, peri-implant disease, mucosal ulcerations, pericoronitis, impacted debris or food, poor oral health care, tongue coating, certain foods, improper cleaning of dentures, xerostomia, frequent use of tobacco products, Helicobacter pylori infection, and other medical conditions $(3,4,5)$.

In most of the cases halitosis is significantly related to tongue coating thickness, periodontal pocket depth, lower intake of beverages, and no food consumption within 2 hours prior to oral examination. 
Bad breath can be a sign of other health problems in about $15 \%$ of the cases $(6,7)$.

A total of $23.6 \%$ of children examined by mouth-breathing had no mouth odor, $12.7 \%$ had mild odor, $12.7 \%$ had moderate odor and $50.9 \%$ had strong odor. The authors found a statistically significant association between halitosis and mouth breathing (8).

In 2007 in Brazil the prevalence of persistent oral malodor was $15 \%$. Halitosis was about three times higher in men than in women, regardless of age. The results show more than three times higher unpleasant oral odor in people over 20 years of age compared with those aged 20 years or under (9).

In another study in 2013 out of the 38 patients, 14 were diagnosed with halitosis, but there was no correlation between the halitosis and either age or gender (10).

Halitosis was statistically higher in men compared to women and there were statistically significant variations between women and men in the righthanded participant group, while there were no statistically significant contrast among the left-handers (11).

The results of Villa A. et al. in 2014 suggest that halitosis in children is related to poor oral hygiene and may be more common in females and older individuals (12).

\section{AIM}

To investigate the presence and degree of halitosis in healthy patients and to compare its incidence in relation to age and gender.

\section{MATERIALS AND METHODS}

We examined 79 healthy patients at an average age of 45.7 (range 3-82). The men included in this investigation were at an average age of 42.1 , and the women's age was 46.2 years.

With an apparatus for measuring bad breath we investigated the levels of odor in patients. We used HC-212SF FitScan Breath Checker of Tanita Corporation of America, Inc. The apparatus quantifies volatile sulfur compounds, hydrogen sulphide (H2S), mercaptan $(\mathrm{CH} 3 \mathrm{SH})$, dimethylsulfide (CH3-S-CH3) and hydrocarbon from the mouth on a scale from 0 to 5 . It operates with a semiconductor gas sensor. The nature of the odors is classified into six grades - 0 : no odor, 1: barely noticeable, 2 : slight but clearly noticeable, 3: moderate, 4: strong and 5: very strong.

When the apparatus is switched on we must wait for about five seconds for it to calibrate. The time is counted on the display with the values being from 5 to 0 . As soon as the unit is ready for testing it beeps. The patient should blow from a distance of about one centimeter. If the patient does not blow immediately after the beeper or does not hit the sensor the unit display indicates error. This reduces the possibility of errors. After 500 samples, including errors, the unit stops working because the integrity of the data is considered to already be high enough.

\section{RESULTS AND DISCUSSION}

The value of bad breath for the 15 individuals under the age of 18 was $0.87(\mathrm{SD} \pm 1.36)$, median 0 , rank $0-5$. For the 32 patients in the $19-50$ years old group, the average value was 1 ( $\mathrm{SD} \pm 0.98$ ), median 1 , rank 0-3. For the 32 individuals in the group of over 51 years old the average value was $1.5(\mathrm{SD} \pm 0.95)$, median 2, rank 0-3.

We observed an increase of the values of bad breath with the increase of age. The increase was also both in the average and the median respectively 0,1 and 2 in the three groups (Fig 1).

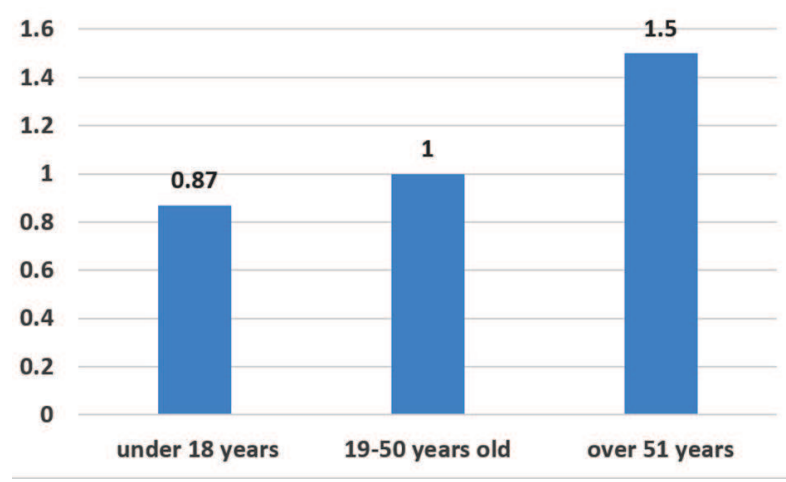

Figure 1. Averages values of bad breath according to age.

Of all tested individuals about one-third did not show any bad odor, while 77 percent had some degree of positive result. The lowest values of the positive result - 1 and 2 were also found in about onethird of the patients.

We did not observe a value of 4 , and the highest value of 5 we found only in one child (Tab. 1). 
Bad Breath and Its Association with Age and Gender

\begin{tabular}{l|cc}
\hline \multicolumn{3}{|c}{ Table 1. Distribution of the degree of bad breath } \\
$\begin{array}{l}\text { Degree of bad } \\
\text { breath }\end{array}$ & $\begin{array}{c}\text { Number of } \\
\text { patients }\end{array}$ & $\%$ of all \\
0 & 26 & $32.9 \%$ \\
1 & 23 & $29.1 \%$ \\
2 & 22 & $27.8 \%$ \\
3 & 7 & $8.9 \%$ \\
4 & 0 & $0 \%$ \\
5 & 1 & $1.3 \%$ \\
\hline
\end{tabular}

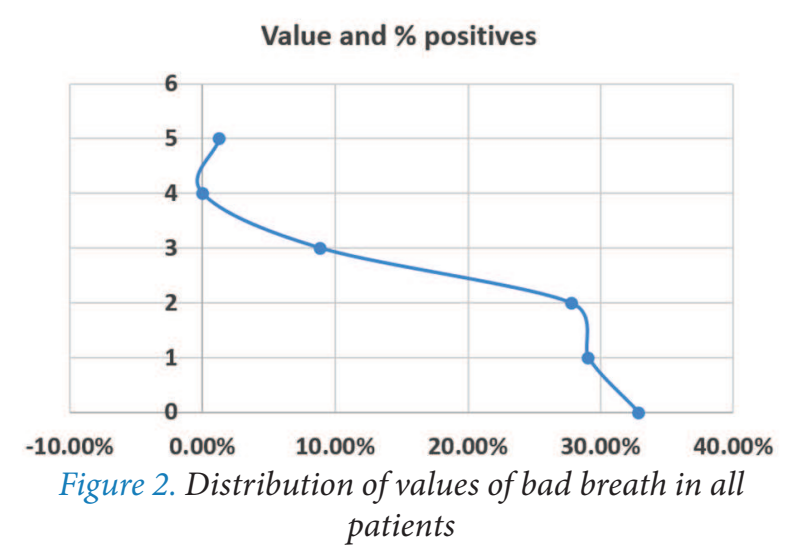

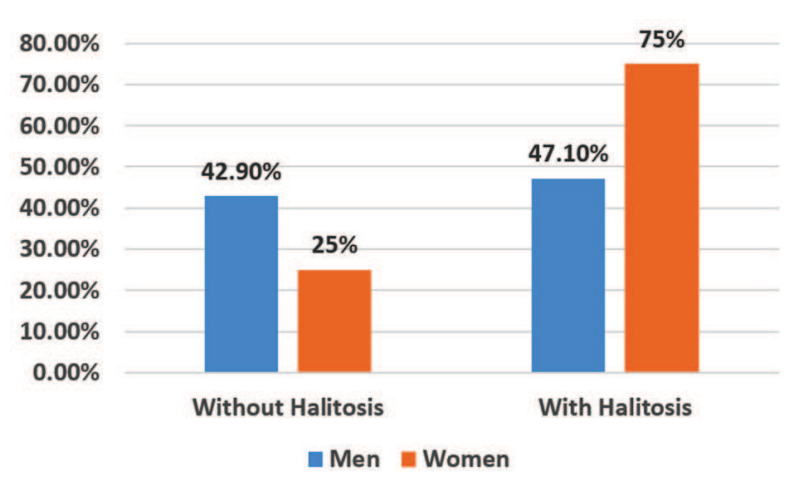

Figure 3. Presence or absence of bad breath in men and women

much more rarely (Fig. 3), which is in contrast with the results of Ciçek Y et al. in 2010 (11).

In men, divided into three age groups, we can see the increase of both the average and the median with the increase of age. The increase in the values of bad breath is relatively uniform with the increase in age (Tab. 3).

In girls under 18 years we found an average of 1.33 , which comes close to the value of elderly men. The highest values were observed again in elderly patients (Tab. 4).

Table 2. Distribution of the degree of bad breath by gender

\begin{tabular}{l|cc|c|cc|c} 
& 0 & 1 & 2 & 3 & 4 & 5 \\
men & $15(42.9 \%)$ & $11(31.4 \%)$ & $(20 \%)$ & $2(5.7 \%)$ & $0(0 \%)$ & $0(0 \%)$ \\
women & $11(25 \%)$ & $(27.3 \%)$ & $15(34.1 \%)$ & $5(11.4 \%)$ & $(0 \%)$ & $1(2.2 \%)$ \\
\hline
\end{tabular}

Table 3. Values for bad breath in men according to age

\begin{tabular}{lccc} 
Men & average & SD \pm & median \\
Under 18 years old (rank 3-12) & $0.56 \%($ rank 0-2) & \pm 0.73 & 0 \\
$19-50$ years (rank 30-50) & $0.81($ rank 0-3) & \pm 0.91 & 1 \\
Over 51 years (rank 51-77) & $1.38($ rank 0-3) & \pm 1.06 & 1.5 \\
\hline
\end{tabular}

Our results showed that a large percentage of men did not have bad breath - $43 \%$ (Tab. 2). It is noteworthy that we reported higher index values in women with value 3 twice more common in women; and women with value 2 were also more than men - 34 versus 20 percent.

Our study showed that $43 \%$ of men and $25 \%$ of women did not suffer from halitosis. We can clearly see from this indicator that men have bad breath
In all age groups both average and median were higher in women. In both sexes the highest values were registered in the oldest patients. The median in both sexes appears to increase with age. In children the values are lower.

As in any age group and in the total patient group the values of bad breath were higher in women compared with those of men. Viewed as median the values in both sexes were 1 . The median has no 
Table 4. Values for bad breath in women according to age

\begin{tabular}{|c|c|c|c|c|}
\hline \multicolumn{5}{|c|}{ Women } \\
\hline \multicolumn{4}{|c|}{ Under 18 years old (rank 6-11) } & $1.33(\mathrm{ral}$ \\
\hline \multicolumn{4}{|c|}{$19-50$ years (rank 28-50) } & $1.19(\mathrm{ral}$ \\
\hline \multicolumn{4}{|c|}{ over 51 years (rank 51-82) } & $1.54(\mathrm{ra}$ \\
\hline \multicolumn{5}{|c|}{ Table 5. Values of bad breath by gender } \\
\hline & age & average & $\mathrm{SD} \pm$ & median \\
\hline men & $\begin{array}{c}26.3 \\
\text { (rank 3-77) }\end{array}$ & 0.88 & \pm 0.93 & 1 \\
\hline women & $\begin{array}{c}48.9 \\
\text { (rank 6-82) }\end{array}$ & 1.39 & \pm 1.13 & 1 \\
\hline
\end{tabular}

bearing on a large group of respondents. Our conclusion confirms the results of Villa A et al. in 2014 (12).

\section{CONCLUSION}

We obtained a result of 0.87 for the group under 18 years old, 1 for the group 19-51 years old and 1.5 for the group over 51 years. In our study the average value was 0.88 for men and 1.39 for women.

Of all tested individuals about one-third did not show any bad breath, while 77 percent had some degree of positive result. Considering the condition in relation to gender, we observed that $43 \%$ of men and $25 \%$ of women did not suffer from halitosis.

About $29 \%$ had the lowest positive value - 1, value 2 - about $28 \%$ and only $1.3 \%$ had a very high degree of halitosis.

Our studies indicated augmentation of the values of bad breath with the increase in age. Women had bad breath more often than men. In all age groups we observed higher degree of bad breath in women.

\section{REFERENCES}

1. Tomás Carmona I, Limeres Posse J, Diz Dios P, Fernández Feijoo J, Vázquez García E, Extraoral etiology of halitosis. Med Oral. 2001 Jan-Feb;6(1):40-47.

2. Mokeem SA. Halitosis: a review of the etiologic factors and association with systemic conditions and its management. J Contemp Dent Pract. 2014 Nov 1;15(6):806-811.

3. Cortelli JR, Barbosa MD, Westphal MA. Halitosis: a review of associated factors and therapeutic approach. Braz Oral Res. 2008;22 Suppl 1:44-54.

4. Krasteva A, Panov Vl., Krasteva A., Kisselova A. Oral cavity and systemic diseases - Helicobacter pylori and dentistry. Biotechnol \& Biotechnol EQ. 2011;25:2447-2451.

5. Krasteva A, Kisselova A, Dineva V, Panov V1, Ivanova A, Krastev Z, Presence of helicobacter pylori in patients with oral malodor. J of IMAB 2013; 19(4):419-421.

6. Guglielmi M, Beushausen M, Feng C, Beech A, Baur D, Halitosis as a product of hepatic disease. SADJ. 2014 Sep;69(8):364-367.

7. Panov Vl. Oral manifestations of hepatitis $\mathrm{C}$ virus, J of IMAB 2013, 19(4):377-379.

8. Motta LJ, Bachiega JC, Guedes CC, Laranja LT, Bussadori SK., Association between halitosis and mouth breathing in children Clinics (Sao Paulo). 2011 Jun; 66(6): 939-942.

9. Nadanovsky P, Carvalho LB, Ponce de Leon A., Oral malodour and its association with age and sex in a general population in Brazil. Oral Dis. 2007 Jan;13(1):105-109.

10. Evirgen S, Kamburoğlu K, Gulsahi A. Effect of clinician's experience, age, gender and calibration on the assessment of halitosis. Oral Health Prev Dent. 2013;11(1):17-22.

11. Ciçek Y, Arabaci T, Canakçi CF.Evaluation of oral malodour in left- and right-handed individuals. Laterality. 2010 May;15(3):317-326.

12. Villa A, Zollanvari A, Alterovitz G, Cagetti MG, Strohmenger L, Abati S. Influence of different toothpaste abrasives on the bristle end-rounding quality of toothbrushes. Int J Dent Hygiene 12, 2014; 208-212. 